NASA Technical Memorandum 106292

AIAA-93-2225

\title{
Derated Ion Thruster Development Status
}

Michael J. Patterson and Thomas W. Haag

Lewis Research Center

Cleveland, Ohio

and

George J. Williams, Jr.

Princeton University

Princeton, New Jersey

Prepared for the

29th Joint Propulsion Conference and Exhibit

cosponsored by the AIAA, SAE, ASME, and ASEE

Monterey, California, June 28-30, 1993

\section{N/SN}


AIAA 93-2225

\title{
DERATED ION THRUSTER DEVELOPMENT STATUS
}

\author{
Michael J. Patterson* and Thomas W. Haag \\ National Aeronautics and Space Administration \\ Lewis Research Center \\ Cleveland, Ohio 44135 \\ George J. Williams, Jr. ${ }^{* *}$ \\ Department of Mechanical and Aerospace Engineering \\ Princeton University \\ Princeton, New Jersey 08540
}

\begin{abstract}
A $30 \mathrm{~cm}$ diameter xenon ion thruster is under development at NASA to provide an ion propulsion option for auxiliary and primary propulsion on missions of national interest. Specific efforts include thruster design optimizations, component life testing and validation, vibration testing, and performance characterizations. Under this program, the ion thruster will be brought to engineering model development status. This paper discusses the activities and preliminary test results to develop a $30 \mathrm{~cm}$ engineering model thruster.
\end{abstract}

\section{Introduction}

There are potential near-term missions such as orbitraising and station-keeping that would benefit from the use of ion propulsion. These benefits may be derived in a number of ways including reduced launch mass, and/or increased spacecraft lifetime on-orbit. A number of flight experiments and demonstrations of ion propulsion are being conducted by the Europeans and Japanese during this decade. ${ }^{1-3}$ In the United States, NASA has an on-going program to develop ion thruster system technologies to satisfy auxiliary and primary propulsion requirements of a number of missions of national interest.

A series of test programs has been conducted with laboratory-model inert gas $30 \mathrm{~cm}$ ion thrusters and components to establish a database for development of an engineering-model thruster. These include identifying wear-mechanisms and design modifications at high (5 and $10 \mathrm{~kW}$ ) input power levels ${ }^{4,5}$; establishing baseline performance on xenon and krypton propellants ${ }^{6,7}$; evaluating alternative discharge chamber, ion optics, and neutralizer designs $^{8-11}$; determining performance and lifetime limits at low $(\leq 2000 \mathrm{~s})$ specific impulse ${ }^{12}$; conducting wear testing of hollow cathodes ${ }^{13,14}$; and evaluating the implica- tions of derating the $30 \mathrm{~cm}$ ion thruster for use on power-limited spacecraft. ${ }^{15,16}$ The derated approach affords potential advantages in performance and operations and in ground qualification test requirements.

An activity is on-going to develop an engineering-model $30 \mathrm{~cm}$ derated xenon ion thruster. The goals of this effort are to develop a thruster with the following attributes:

- compatibility with the varied mission requirements of both auxiliary and primary propulsion functions;

- capability of operating over an input power envelope of at least 0.5 -to-5.0 $\mathrm{kW}$ with $10,000 \mathrm{~h}$ lifetime;

- reduced size, mass, parts count, and fabrication costs from state-of-the-art;

- simplified operation and interfaces that leverage prior development efforts at NASA and elsewhere.

Additionally NASA is pursuing the transfer of this technology to industry via loans of thruster system hardware and drawing-packages.

The specific activities on-going to develop an engineering model thruster include thruster design optimizations, development of a Computer-Aided-Design-(CAD)-based thruster drawing package, thruster component life testing

\footnotetext{
Copyright $\odot 1993$ by the American Institute of Aeronautics and Astronautics, Inc. No copyright is asserted in the United States under Title 17, U.S. Code. The U.S. Government has a royalty-free license to exercise all rights under the copyright claimed herein for Government purposes. All other rights are reserved by the copyright owner.

*Aerospace Engineer, Member ALAA

-Graduate Student, student Member AIAA
} 
and validations, vibration testing, and performance characterizations. These activities are to conclude with more detailed characterizations of the thruster interfaces including direct-thrust measurements, power processing requirements, and plumes and electromagnetic-compatibility measurements conducted on functional and engineering model thrusters. Additionally, thruster wear tests are anticipated to verify and demonstrate life requirements, and integration tests with breadboard power processor units. This paper discusses the status of the design and test activities to develop an engineering model $30 \mathrm{~cm}$ derated ion thruster.

\section{Thruster Design}

The lightweight thruster hardware, shown in Figures 1 and 2 , is presently developed to a preliminary engineering, or functional model, status. It has a configuration similar to that which would be used in a flight application, and is being used to validate the physical and functional design, and to define manufacturing processes. This will be followed by an engineering model thruster used to validate the design and prove readiness for production.

The functional model thruster was designed with certain operational and performance goals and objectives. These include: an input power envelope of at least $0.5 \mathrm{~kW}$ to $5.0 \mathrm{~kW}$, with a lifetime of $10,000 \mathrm{~h}$ at all power levels; a performance (specific impulse/efficiency) comparable to that demonstrated previously with $30 \mathrm{~cm}$ laboratory model thrusters ${ }^{46,8,10,12}$; design and interfaces that are compatible with the varied mission and system requirements for both auxiliary and primary propulsion applications; simplified power processing requirements; and reduced thruster size, mass (to approximately $7 \mathrm{~kg}$ ), parts count, and fabrication costs. Some of the primary design objectives for the thruster are summarized in Table 1.

As illustrated in Figure 3, the functional model thruster typically operates on 4 power supplies for steady-state operation ( 2 additional heater supplies for starting), with a total of 7 power leads to the thruster. It is anticipated that the first breadboard power processor for the thruster will however require only a total of 3 power modules. This reduction is implemented by combining functions performed by multiple commercial power supplies into single custom modules, with the benefit of reduced parts count and mass. ${ }^{17}$

The discharge chambers of ion thrusters have traditionally been cylindrical in shape, with a flat circular rear wall. This represents a simple geometry and promotes a uniform plasma distribution across the exit plane. Past development efforts, ${ }^{18}$ however, have shown the large rear wall to be an inefficient stress bearing structure, and vulnerable to mechanical vibration. One innovation of the present lightweight thruster design involves selection of a geometry which is inherently more rigid, while still exhibiting good discharge characteristics. A modified conic geometry was selected as a basis for the design. This shape greatly reduced the diameter of the rear wall, which was the weakest structural element of previous thrusters. The conic shape transitions into a short cylindrical region immediately upstream of the exit plane. The cylindrical transition adds structural stiffness as compared to a pure conic geometry.

The modified conic geometry represents a more complex shape than that of a simple cylinder. A different fabrication technique was sought in order to avoid weaknesses associated with segmented construction. Both die stamping and spin forming permit seamless formation of complex shapes from a single sheet of metal. Because of its lower initial tooling cost, metal spinning is often preferred for low volume production. The main discharge chamber, as well as magnet retention rings and stiffeners were spun formed from $0.8 \mathrm{~mm}$ thick alloy 1100 aluminum. While 6061 aluminum would be considerably stronger, alloy 1100 is more commonly used in spin forming because it is soft and can be shaped quickly. Higher strength metals can be spun in a similar way but need periodic annealing and may possibly require use of a steel mandrel. This added expense was judged unnecessary for a preliminary engineering model thruster and so 1100 aluminum was selected.

The use of non-ferromagnetic structural materials in the chamber design is the second major departure from conventional divergent-field and ring-cusp thruster designs. This approach was based on prior testing efforts with laboratory model thrusters ${ }^{9}$, and recognizes that the primary mass driver for conventional thrusters is the discharge chamber. The magnetic circuit employed in the discharge is of ring-cusp design. ${ }^{8}$ It uses high-field strength rare earth permanent magnets in rings of alternating polarity along the perimeter of the chamber, with the field lines terminating on anode potential surfaces. Three cusps are located in the discharge, one each in the region of the discharge cathode, the discharge sidewall (at the conic-cylinder intersection), and the ion optics-end.

The baseline ion optics system is the two-grid design developed for the engineering model mercury ion thrust- 
er. ${ }^{18}$ The electrodes are fabricated from molybdenum, and have nominal thicknesses of $0.38 \mathrm{~mm}$ for both the screen and accelerator grids. The apertures are of cylindrical shape, with inner circle diameters of $1.91 \mathrm{~mm}$ and 1.14 for the screen and accelerator grids, respectively. The open-area-fraction of the screen grid is 0.67 , and 0.24 for the accelerator grid. The nominal cold grid gap is set at $0.66 \mathrm{~mm}$. The electrode geometries for the baseline optics are listed in Table 2. Typical minimum accelerator grid voltages for these optics are shown in Table 3.

The discharge chamber and neutralizer cathode assemblies are similar to those implemented in previous laboratory-model ring-cusp thrusters, and used in wear tests. ${ }^{4,11-15}$ They consist of a hollow cathode subassembly composed of a high temperature refractory alloy and an insert impregnated with a low-work function compound. Both assemblies also use a swaged heater design derived from the mercury ion thruster, used for both activation and ignition of the cathodes.

The discharge hollow cathode does not employ a keeper or starting electrode and discharge-coupling to the anode is used for ignition and steady-state operation. With the screen grid electrode electrically isolated, all cathode potential surfaces in the discharge chamber, except the hollow cathode assembly itself, have been eliminated in this thruster design. This approach reduces the total number of components subjected to sputtering via discharge plasma ions to an absolute minimum. The neutralizer cathode assembly incorporates an enclosedkeeper electrode design to improve gas efficiency, with critical design parameters established to maximize ion transparency and reduce beam-coupling potentials.

The selection of a high-voltage propellant isolator design - either high-pressure, or low-pressure fed - is contingent on whether the propellant flow rate to the thruster must be varied during thruster operation, how much volume is available on the thruster to accommodate feed system elements, and where the thruster/propellant system interface is drawn. The flow rates to the thruster may require active variation to accommodate power-throttling of the thruster, and/or to augment flow rates to the discharge and neutralizer cathodes during ignition.

The use of a high-pressure isolator design affords some simplification in the thruster/propellant system interface and in the thruster propellant line plumbing. This design permits the use of a single propellant line interface to the propellant system, and use of a single high-voltage isolator, as illustrated in Figure 4. Integral flow restrictors of appropriate orifice sizes may then be incorporated into the thruster, with two additional lowvoltage low-pressure isolators required for the cathode lines. This approach however can not accommodate flow variations for power throttling or for cathode ignition (if required). Substituting integral flow control devices for the restrictors is somewhat problematic due to volume and location constraints on the thruster. "Off-loading" the controllers from the thruster to the propellant system is also problematic in that this portion of the feed system will require isolation from spacecraft potential and, like the thruster, will require a plasma screen.

The use of a low-pressure high-voltage isolator design results in a more complex thruster/propellant system interface, but readily permits flow variations to accommodate throttling. Additionally low-pressure isolators are typically more complex and require larger volumes than a high-pressure design. Figure 5 illustrates this approach. Three propellant lines are required to interface the thruster and propellant system, with two high-voltage isolators for the main plenum and discharge cathode, and a single low-voltage isolator for the neutralizer.

For purposes of performance characterizations and wear testing, the functional model thruster uses a low-pressure high-voltage isolator approach. The approach implemented on the engineering model thruster will be contingent on results from on-going propellant isolator studies, investigations of the starting characteristics of the discharge and neutralizer cathodes, and on specific mission requirements.

Preliminary test data indicate that a modified commercially-available cryogenic electrical break, designed for use with liquid nitrogen lines, may readily accommodate the thruster high-voltage propellant isolator requirements for both low-pressure and high-pressure applications. A cryogenic break, with external dimensions of $0.64 \mathrm{~cm}$ diameter and $2.2 \mathrm{~cm}$ length, when packed with ceramic beads, can withstand at least 2.5 kilovolts operating at low-pressure conditions on xenon (with negligible pressure-drop), and at least 3 kilovolts at high-pressure (nominally one atmosphere). ${ }^{19}$ These devices are also being used as low-cost, ultra-high vacuum low-voltage isolators for life testing of hollow cathodes.

\section{Thruster Test Results}

\section{Performance}

Preliminary performance data for the thruster have been obtained over the 1.0-3.0 kW power envelope. These 
tests have been conducted to: (1) quantify the baseline discharge chamber performance and stability, and identify and verify any required magnetic circuit modifications, and; (2) obtain overall thruster performance data.

Bench-test measurements indicated a reduced internal magnetic flux density with the conic-aluminum discharge chamber design as compared to the conventional cylindrical-steel designs employed in previous laboratory model thrusters. Hence reduced discharge chamber, and overall thruster, performance was anticipated as a trade-off for reduced mass, although the magnitude of the potential performance degradation could not be quantified a priori.

Initial discharge chamber performance data indicated a high sensitivity of discharge voltage-to-cathode flow rate. This sensitivity was more marked as the thruster input power (discharge and beam currents) was increased. Subsequent modifications to the thruster magnetic circuit were made to reduce the sensitivity of the discharge voltage to variations in cathode flow rate, and to increase the magnitude of the cathode flow rate. These changes in magnetic circuit were made by varying the number and size of the magnets at each cusp, thereby changing the flux density in the discharge chamber. No changes in spatial location of the cusps with respect to the discharge were made.

It was identified that factor-of-two variations in cusp field strengths at the sidewall and ion optics-end cusps had no impact on discharge stability or electrical efficiency. However, modest $(30-40 \%)$ variations in the magnetic field strength in the region of the discharge cathode resulted in order-of-magnitude changes to the discharge stability, as measured by the sensitivity of the discharge voltage to variations in cathode flow rate. Figure 6 shows the sensitivity of the discharge voltage to variations in cathode flow rate for both the initial and modified magnetic circuit geometries. Again, however, no impact on discharge chamber efficiency was observed.

Figure 7 shows the discharge chamber losses of the functional model lightweight thruster at a nominal input power of $1.7 \mathrm{~kW}$. The discharge losses for the functional model thruster are approximately $35 \mathrm{~W} / \mathrm{A}$ higher than that of previous laboratory-version thrusters for the same operating condition. At a fixed discharge voltage of 28 volts, this reduced electrical efficiency results in approximately 1-2 A higher cathode emission current to obtain the same discharge propellant efficiency. From an overall thruster performance standpoint, this reduced discharge electrical efficiency has only a very modest impact. At the highest propellant efficiency conditions identified in Figure 7, the functional model thruster has an efficiency of $59 \%$ at a specific impulse of $2930 \mathrm{~s}$, compared to the laboratory-version thruster which has an efficiency of $58 \%$ at $3060 \mathrm{~s}$. Figure 8 shows the overall thruster efficiency versus specific impulse for the functional model thruster. Additional tests to improve discharge electrical efficiency and stability are under active investigation.

\section{Vibration}

The thruster has undergone a series of low level sine sweep vibration tests conducted at the NASA Lewis Research Center's Structural Dynamics Laboratory. The objective of these tests was to investigate the general behavior of the thruster to evaluate its vibration characteristics and to provide information on its vibration strength. This activity was conducted early in the thruster development effort so that if objectional resonances or inadequate strengths were identified, modifications to thruster design could be quickly corrected. The thruster configuration for these tests did not include a plasma screen, or propellant isolators. Additionally, the thruster was equipped with the baseline ion optics, which had previously demonstrated their vibration worthiness. ${ }^{18}$

The tests consisted of applying an excitation frequency from $5 \mathrm{~Hz}$ to $2 \mathrm{kHz}$ at a one octave per minute sweep rate at amplitudes of 0.5 and $1.0 \mathrm{~g}$ through the three orthogonal axes identified in Figure 9. The intention was to determine the natural frequencies of the thruster and obtain information regarding the non-linearity of response with increased excitation level. A total of 19 accelerometers were installed on the thruster to measure local structural response at various locations. Figure 10 shows the thruster mounted on the vibration table.

Table 4 lists some of the dominant resonant frequencies exhibited by the thruster. These were determined by identifying resonant peaks with an acceleration magnitude at least 10 times that of the excitation frequency. It is noted that some whole body displacements at approximately $25 \mathrm{~Hz}$ were large enough to be readily observed during the test, although the accelerations were less than 10 times that of the excitation frequency. These occurred as the thruster rocked about the axis through the thruster gimbal pads (see Fig. 9). This motion is exhibited in the acceleration versus frequency plot for the discharge cathode (input amplitude of $0.5 \mathrm{~g}$, through Y-axis) in Figure 11. This was attributable to the flat metal bracket interface of the gimbal pad which was not adequately stiff in torsion. The brackets have been subsequently rede- 
signed to increase their torsional stiffness.

Accelerometers in the region of the neutralizer assembly also indicated potentially unacceptable stresses may be incurred at higher input amplitudes. The neutralizer has subsequently undergone significant redesign to reduce its mass and length. The new design is cylindrical in geometry with external dimensions of approximately $2.2 \mathrm{~cm}$ diameter by $12 \mathrm{~cm}$ length, with a mass of approximately $115 \mathrm{~g}$, and it has a parts count approximately one orderof-magnitude lower than that of the mercury ion thruster neutralizer design.

No damage to the thruster was incurred during the conduct of the test, and no deterioration was identified during subsequent disassembly. However the test did indicate areas for design modification and improvement. Additional tests, with the plasma screen and propellant isolators, at high amplitudes will be required to fully validate the structural integrity of the design.

\section{Component Life Testing}

A test program is on-going to develop and validate hollow cathode technology for the space station Freedom plasma contactor program. ${ }^{20}$ Much of the technology, and cathode components, for the thruster are common with the plasma contactor including cathode tube, insert, low voltage propellant isolator, keeper, and heater subassemblies. Hence, much of the life test and performance data derived from the hollow cathode contactor activity is directly transportable to the engineering model thruster development. These activities include hollow cathode and heater life testing and validation, definition and validation of contamination control protocols and procedures, definition and verification of conditions for cathode ignition, and development of cathode storage, handling and activation requirements.

\section{Documentation}

A CAD drawing package for the functional model thruster is under development, using CADAM. ${ }^{21}$ The drawing package consists of approximately 250 drawings and includes all thruster subsystems and associated fabrication, assembly, and inspection procedures. The $\mathrm{CAD}$ drawing package will be provided to industry as part of the ion thruster technology transfer program.

Additionally, full procurement specifications for critical cathode components such as the insert are being developed. These specifications include definition of all critical aspects of the chemical and physical makeup to insure procurement of a reliable product for flight, and definition of the required level of documentation of materials and processes used by the manufacturer of the component in its production.

\section{Development Activities}

Some remaining activities to develop and validate a 30 $\mathrm{cm}$ engineering model ion thruster include:

- complete performance documentation on the functional model thruster, and resolve remaining mechanical design issues;

- define and verify conditions for discharge chamber and neutralizer cathode ignition;

- initiate detailed characterizations of thruster interfaces including EMC and plume surveys;

- initiate wear testing to verify thruster design and lifetime expectations, and;

- initiate thruster/breadboard power processor integration testing.

Summary
A $30 \mathrm{~cm}$ diameter xenon ion thruster is under develop-
ment at NASA to provide an ion propulsion option for
auxiliary and primary propulsion on missions of national
interest. Under this program the ion thruster is being
brought to engineering model development status. Goals
of the development effort include a thruster mass of $7 \mathrm{~kg}$,
and an operating power envelope of 0.5 to $5.0 \mathrm{~kW}$. The
present thruster hardware under test is at a preliminary
engineering, or functional model, level of maturity. The
thruster incorporates major innovations in structural
design, materials, and fabrication techniques compared to
that employed in conventional ion thrusters.

Test data have been obtained over a 1.0-3.0 kW power envelope. These tests were conducted to verify the discharge chamber design and obtain overall thruster performance data. Overall thruster performance is similar to that obtained with laboratory-version thrusters. Additional tests to improve the discharge electrical efficiency are under investigation.

The thruster has undergone a series of low level sine sweep diagnostic vibration tests. The objective of these tests was to investigate the general behavior of the thruster to evaluate its vibration characteristics and to provide information on its vibration strength. The tests consisted of applying an excitation frequency from $5 \mathrm{~Hz}$ to $2 \mathrm{kHz}$ at amplitudes of 0.5 and $1.0 \mathrm{~g}$ through three orthogonal axes. The tests indicated that the thruster has adequate strength while indicating areas for design modification and improvement. Additional activities in support of the thruster development include component life testing, and documentation processes including 
generation of a thruster $\mathrm{CAD}$ drawing package.

\section{Acknowledgements}

The authors would like to express their appreciation to Eli Green, George Jacynycz, Craig Nelson, and Eugene Pleban for test support, thruster assembly and suggestions in design, and Elena Ispas-Fritz for generation of thruster drawings and engineering design support. Additionally, vibration test support and analyses provided by William Scott is gratefully acknowledged.

\section{References}

${ }^{1}$ Groh, K., et. al., "Development Status of the RIT Ion Engines, " AIAA Paper No. 90-2671, July 1990.

${ }^{2}$ Fearn, D.G., "The Proposed Demonstration of the UK-10 Ion Propulsion System on ESA's SAT-2 Spacecraft," IEPC Paper No. 88-031, October 1988.

${ }^{3}$ Kajiwara, K. and Katada, M., "Test Facilities for the ETS-VI Ion Engine System," AIAA Paper No. 90-2656, July 1990.

${ }^{4}$ Patterson, M.J. and Verhey, T.R., "5kW Xenon Ion Thruster Lifetest," AIAA Paper No., 90-2543, July 1990.

${ }^{5}$ Rawlin, V.K., "Internal Erosion Rates of a 10-kW Xenon Ion Thruster," ALAA Paper No. 88-2192, July 1988.

${ }^{6}$ Patterson, M.J. and Rawlin, V.K., "Performance of 10-kW Class Xenon Ion Thrusters," AIAA Paper No. 882914, July 1988.

${ }^{7}$ Patterson, M.J. and Williams, G.J. Jr., "Krypton Ion Thruster Performance," AIAA Paper No. 92-3144, July 1992.

${ }^{8}$ Sovey, J.S., "Improved Ion Containment Using a Ring-Cusp Ion Thruster," Journal of Spacecraft and Rockets, Vol. 21, Sept.-Oct. 1984, pp. 488-495.

${ }^{9}$ Patterson, M.J. and Rawlin, V.K., "Derated Ion Thruster Design Issues," IEPC Paper No. 91-150, October 1991.

${ }^{10}$ Rawlin, V.K., "Characterization of Ion Accelerating Systems on NASA's Ion Thrusters," AIAA Paper No. 923827, July 1992.

${ }^{11}$ Patterson, M.J. and Mohajeri, K., "Neutralizer Optimization," IEPC Paper No. 91-151, October 1991.

${ }^{12}$ Patterson, M.J., "Low-Isp Derated Ion Thruster Operation," AIAA Paper No. 92-3203, July 1992.

${ }^{13}$ Verhey, T.R. and Patterson, M.J., "Microanalysis of Extended-Test Xenon Hollow Cathodes," AIAA Paper No. 91-2123, June 1991.

${ }^{14}$ Sarver-Verhey, T.R., "Extended Testing of Xenon Ion Thruster Hollow Cathodes," AIAA Paper No. 923204, July 1992.

${ }^{15}$ Patterson, M.J. and Foster, J.E., "Performance and
Optimization of a "Derated" Ion Thruster for Auxiliary Propulsion," AIAA Paper No. 91-2350, June 1991.

${ }^{16}$ Rawlin, V.K. and Majcher, G., "Mass Comparisons of Electric Propulsion Systems for NSSK of Geosynchronous Spacecraft," AIAA Paper No. 91-2347, June 1991.

${ }^{17}$ Rawlin, V.K., Pinero, L., and Hamley, J., "Simplified Power Processing for Inert Gas Ion Thrusters," ALAA Paper No. 93-2397, June 1993.

${ }^{18} 30$-Centimeter Ion Thruster Subsystem Design Manual," NASA TM-79191, June 1979.

${ }^{19}$ Personal communication, Mantenieks, M.A., NASALewis Research Center, May 1993.

${ }^{20}$ Patterson, M.J., et al., "Plasma Contactor Technology for Space Station Freedom," ALAA Paper No. 93-2228, June 1993.

${ }^{21}$ CADAM is a registered trademark of International Business Machines. 
Table 1 Functional Model Thruster Design Objectives

\begin{tabular}{||c|c|}
\hline propellant & xenon \\
\hline size & $30 \mathrm{~cm}\{28 \mathrm{~cm}$ beam diameter $\}$ \\
\hline mass & $\approx 7 \mathrm{~kg}$ \\
\hline input power & $0.5-5.0 \mathrm{~kW}$ \\
\hline lifetime & $\geq 10,000 \mathrm{~h}$ \\
\hline
\end{tabular}

Table 2 Ion Optics Electrode Designs

\begin{tabular}{||c||c|c||}
\hline \multicolumn{1}{|c|}{$\begin{array}{c}\text { electrode } \\
\text { design }\end{array}$} & \multicolumn{2}{c|}{$\begin{array}{c}\text { baseline ion } \\
\text { optics electrodes }\end{array}$} \\
\hline attribute & screen & 0.38 \\
\hline $\begin{array}{c}\text { electrode thickness, } \\
\text { mm }\end{array}$ & 0.38 & 1.14 \\
\hline $\begin{array}{c}\text { hole diameter, } \\
\text { mm }\end{array}$ & 1.91 & 0.24 \\
\hline open-area-fraction & 0.67 & \\
\hline
\end{tabular}

Table 3 Ion Optics Measured Performance and Anticipated Lifetime

\begin{tabular}{||c|c||}
\hline \multicolumn{1}{|c|}{ attribute } & $\begin{array}{c}\text { baseline ion optics } \\
\text { electrodes }\end{array}$ \\
\hline $\begin{array}{c}\text { minimum accelerator grid voltage } \\
\text { at } 1.0 \text { A beam current } \\
\text { \{typical\} }\end{array}$ & $-150 \mathrm{~V}$ \\
\hline $\begin{array}{c}\text { minimum accelerator grid voltage } \\
\text { at } 3.0 \text { A beam current } \\
\text { \{typical\} }\end{array}$ & $-300 \mathrm{~V}$ \\
\hline $\begin{array}{c}\text { anticipated accelerator grid in-space } \\
\text { mass loss rate at } 1.0 \text { A beam current }\end{array}$ & $4.6 \mathrm{~g} / \mathrm{khr}$ \\
\hline $\begin{array}{c}\text { anticipated accelerator grid in-space } \\
\text { mass loss rate at } 3.0 \text { A beam current }\end{array}$ & $7.5 \mathrm{~g} / \mathrm{khr}$ \\
\hline
\end{tabular}

${ }^{1}$ Mass loss rate estimates obtained from correlation of xenon ion thruster lifetest results, and are more conservative than those derived from published sputter yield data. Assumptions: molybdenum accelerator grid; in-space accelerator grid impingement current equal to $0.25 \%$ of the beam current value. 
Table 4 Thruster Dominant Resonant Frequencies*

\begin{tabular}{|c|c|c|c|}
\hline \multirow{3}{*}{$\begin{array}{l}\text { location } \\
\text { of } \\
\text { accelerometer }\end{array}$} & \multicolumn{3}{|c|}{ direction of excitation } \\
\hline & $\mathrm{X}$ axis & $Y$ axis & $\mathrm{Z}$ axis \\
\hline & $\begin{array}{c}\max . \mathrm{g} / \text { frequency } \\
(\mathrm{Hz}) \\
\text { at } 1.0 \mathrm{~g}\end{array}$ & $\begin{array}{c}\max . \mathrm{g} / \text { frequency } \\
(\mathrm{Hz}) \\
\text { at } 1.0 \mathrm{~g}\end{array}$ & $\begin{array}{c}\max . \mathrm{g} / \text { frequency } \\
(\mathrm{Hz}) \\
\text { at } 0.5 \mathrm{~g}\end{array}$ \\
\hline $\begin{array}{l}\text { optics-end of thruster, interior of } \\
\text { discharge chamber } \\
\text { \{to observe bending of cylinder\} }\end{array}$ & $\begin{array}{l}13.8 / 580 \\
11 / 645\end{array}$ & - & - \\
\hline $\begin{array}{l}\text { exterior of thruster discharge chamber } \\
\text { near gimbal mounts } \\
\text { \{to observe deflection of gimbal mounts }\end{array}$ & - & $\begin{array}{c}10 / 800 \\
10.3 / 850\end{array}$ & - \\
\hline $\begin{array}{c}\text { exterior of thruster discharge chamber } \\
\text { on conic section } \\
\text { \{to observe deformation of cone }\end{array}$ & $10.7 / 740$ & $15 / 760$ & - \\
\hline $\begin{array}{l}\text { exterior of neutralizer keeper assembly } \\
\text { \{to observe y-axis motion of keeper }\}\end{array}$ & $\begin{array}{c}15.8 / 136 \\
12 / 900\end{array}$ & $18 / 755$ & - \\
\hline $\begin{array}{l}\text { exterior of neutralizer keeper assembly } \\
\text { \{to observe } x \text {-axis motion of keeper }\}\end{array}$ & $14.8 / 135$ & $44 / 770$ & $13 / 800$ \\
\hline $\begin{array}{c}\text { exterior of neutralizer assembly } \\
\text { \{to observe y-axis motion of assembly\} }\end{array}$ & $13 / 140$ & $13 / 770$ & - \\
\hline $\begin{array}{c}\text { exterior of neutralizer assembly } \\
\text { \{to observe } x \text {-axis motion of assembly }\end{array}$ & - & $11 / 770$ & - \\
\hline $\begin{array}{c}\text { ion optics mount } \\
\text { \{to observe radial deflection }\end{array}$ & - & $\begin{array}{c}11 / 800 \\
10.5 / 830 \\
\end{array}$ & - \\
\hline $\begin{array}{c}\text { ion optics mount } \\
\text { \{to observe axial deflection }\end{array}$ & $14.5 / 900$ & - & - \\
\hline $\begin{array}{c}\text { exterior of thruster discharge chamber } \\
\text { near ion optics mount } \\
\text { \{to observe deformation in aluminum } \\
\text { discharge chamber caused by ion optics }\end{array}$ & $11 / 890$ & $10.8 / 860$ & - \\
\hline $\begin{array}{c}\text { rear of discharge cathode assembly } \\
\text { \{to observe axial motion }\end{array}$ & $10.5 / 600$ & - & - \\
\hline $\begin{array}{c}\text { center of ion optics accelerator grid } \\
\text { \{to observe deformation of ion optics\} }\end{array}$ & $\begin{array}{l}12 / 700 \\
12 / 740\end{array}$ & $\begin{array}{l}18 / 760 \\
15 / 785 \\
18 / 815\end{array}$ & - \\
\hline
\end{tabular}

* resonant acceleration peaks with a magnitude at least 10 times that of the excitation frequency 


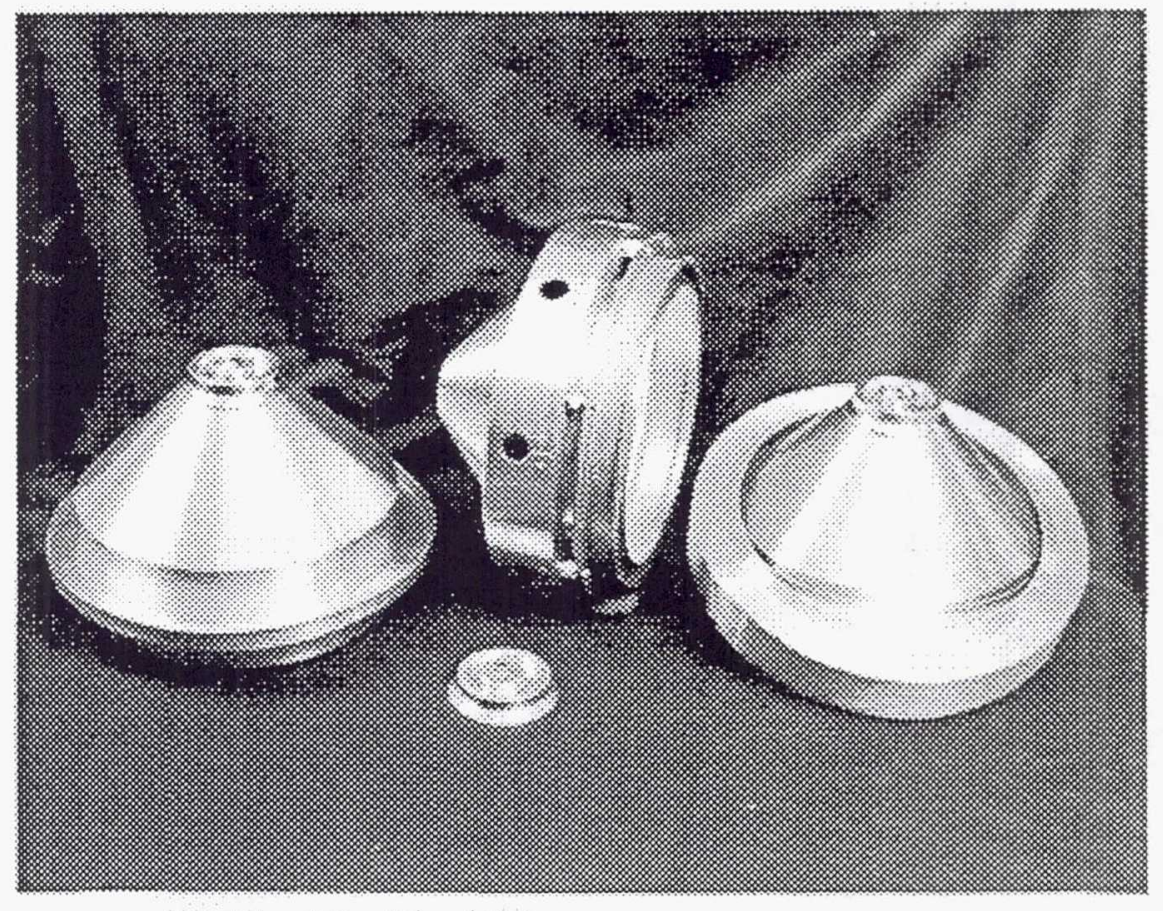

Fig. 1 Discharge chambers for functional model thrusters.

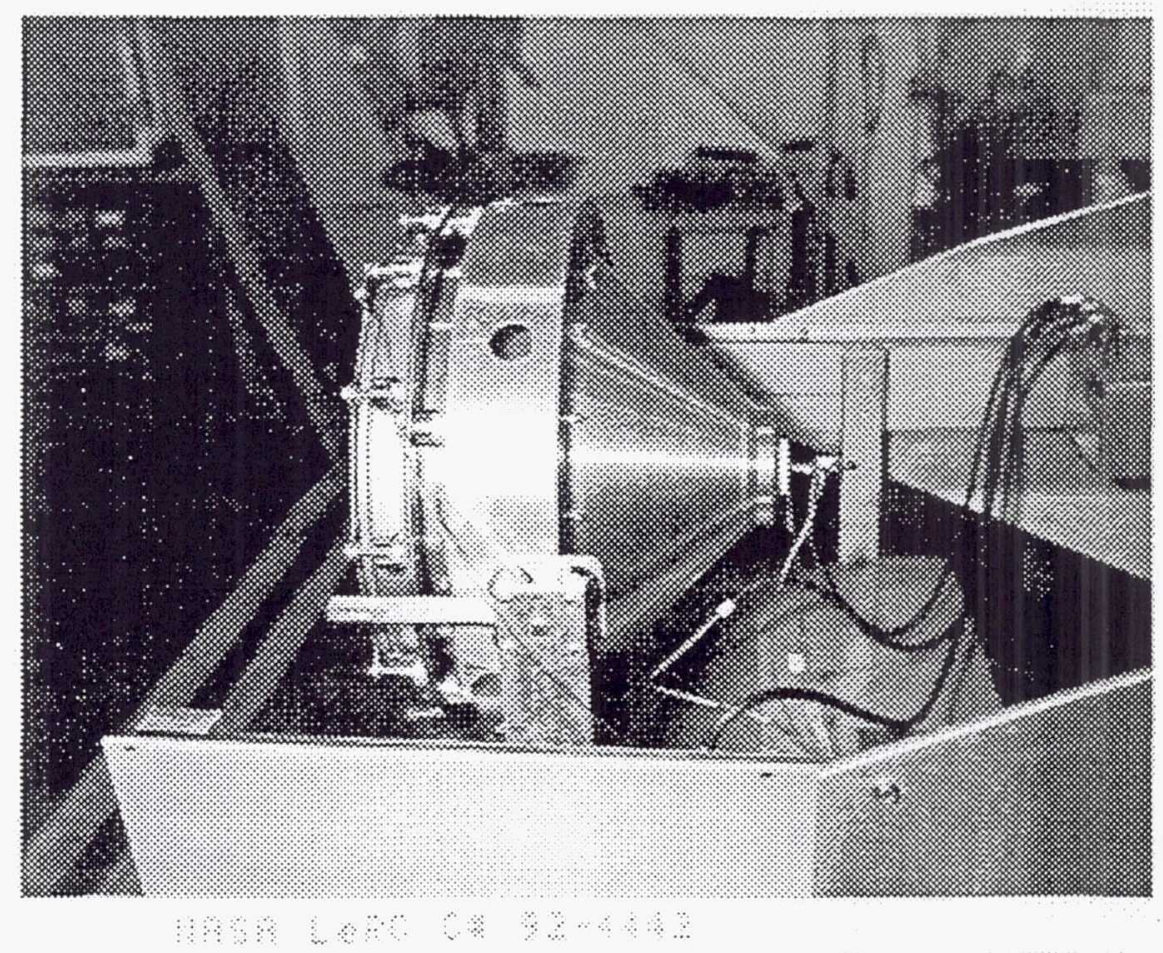

Fig. 2 Functional model thruster on test stand. 


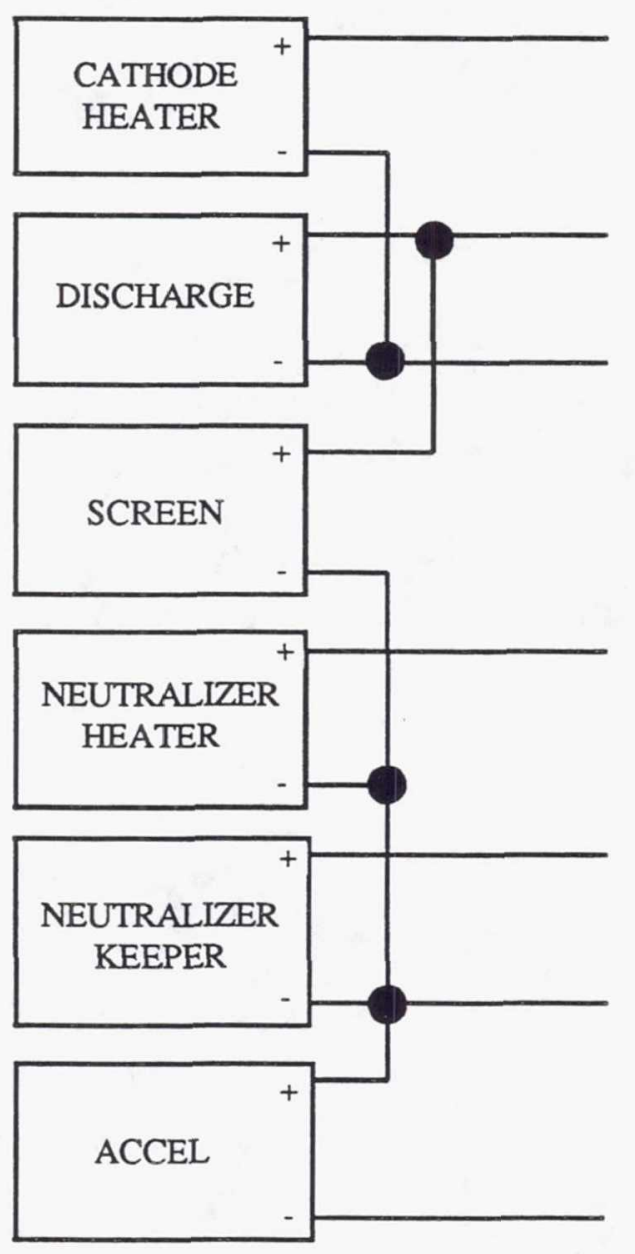

Fig. 3 Thruster power supply circuit diagram. 


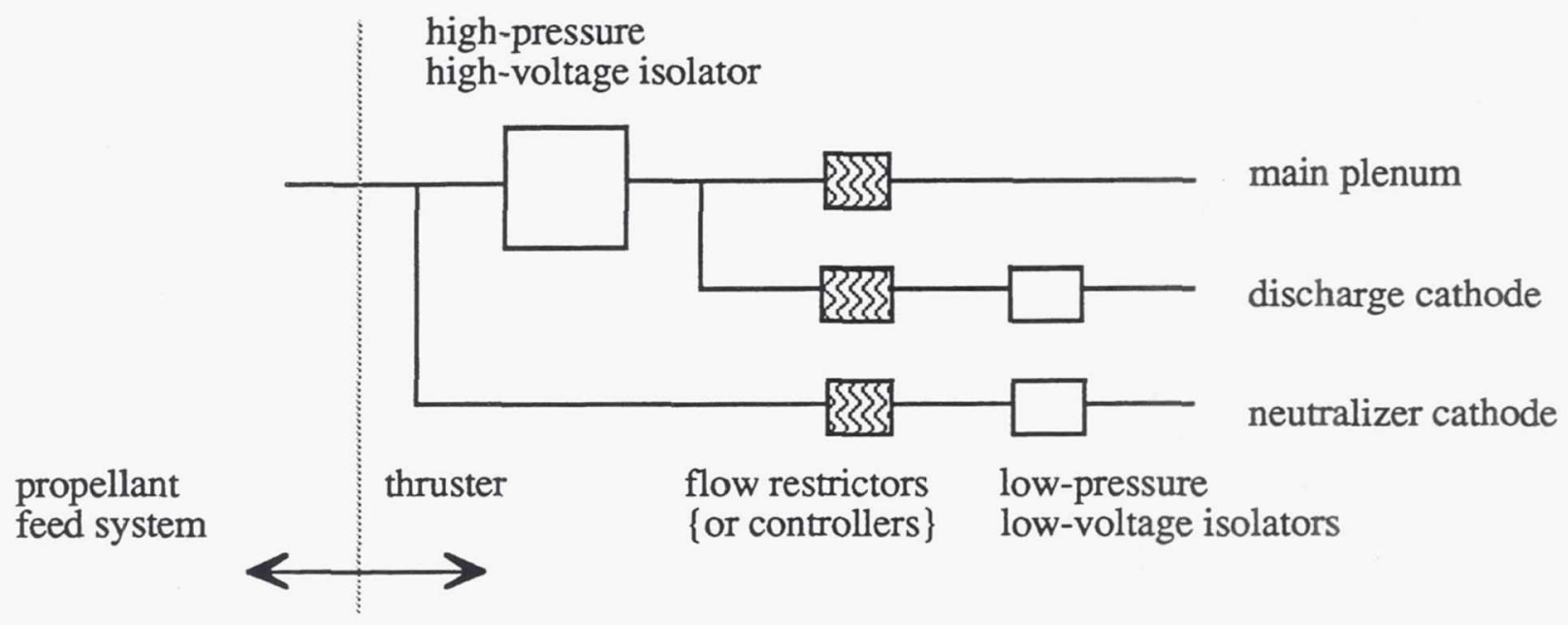

Fig. 4 Thruster configuration with single high-pressure, high-voltage isolator.

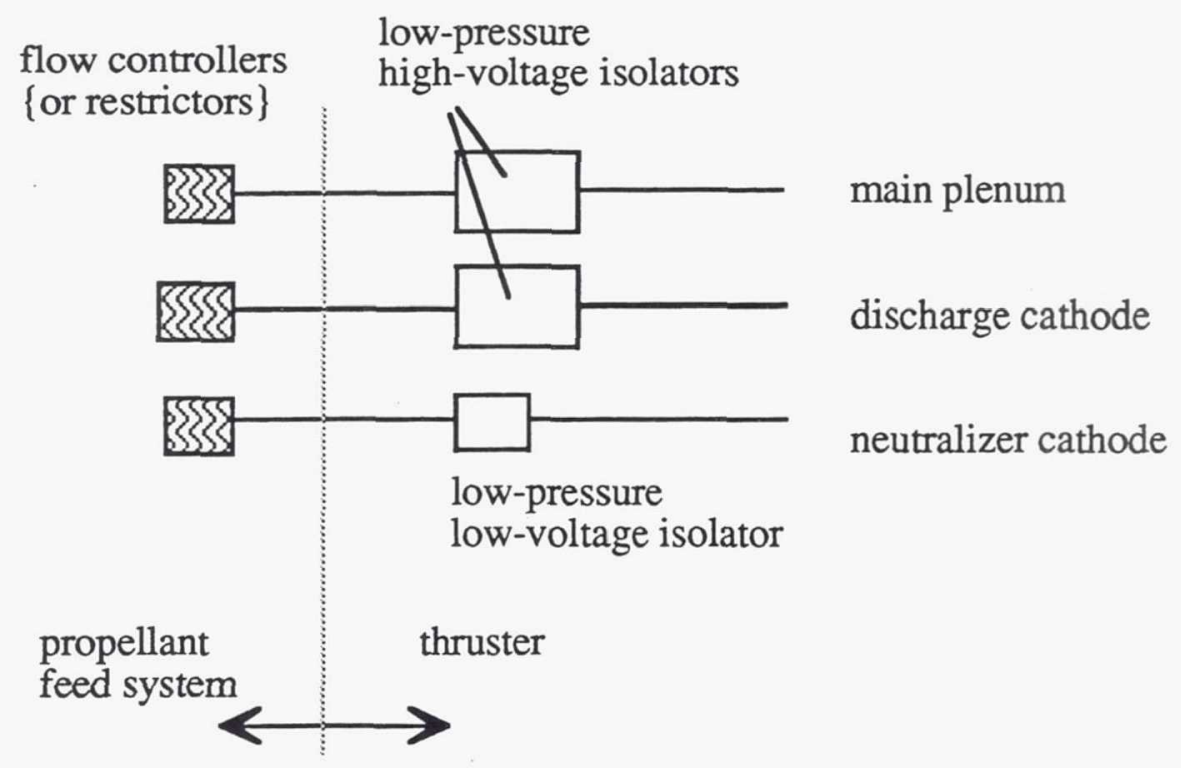

Fig. 5 Thruster configuration with low-pressure, high-voltage isolators. 


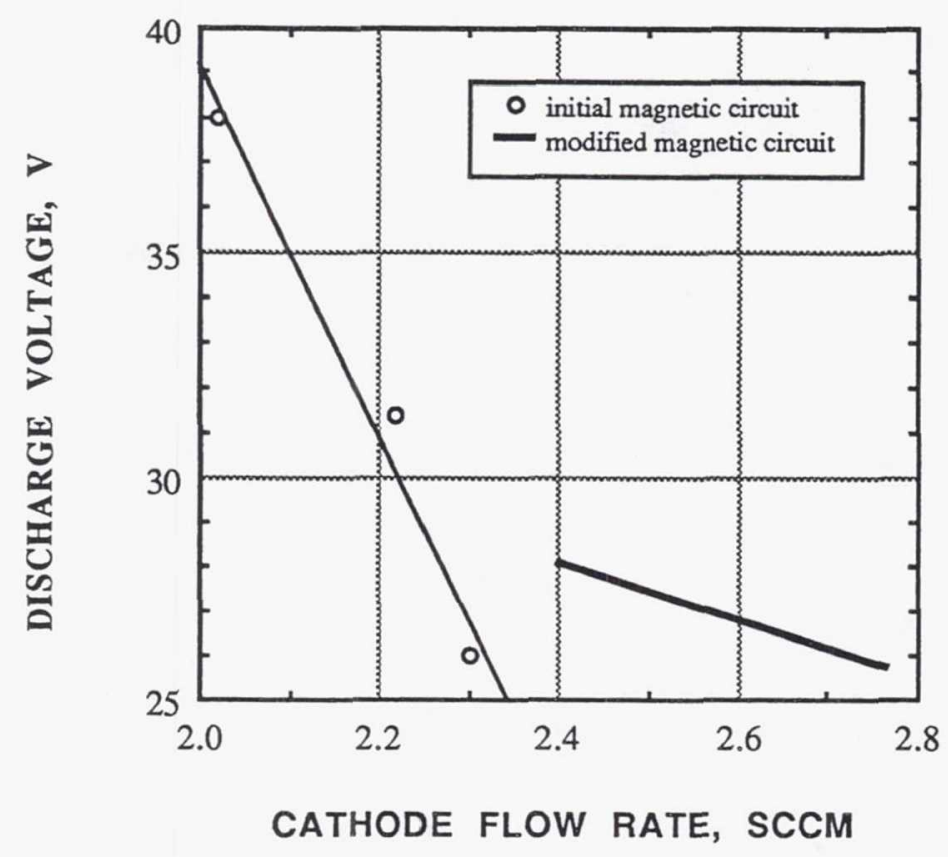

Fig. 6 Sensitivity of discharge voltage to variations in cathode flow rate; $2.4 \mathrm{~A}$ beam current, $2.9 \mathrm{~kW}$.

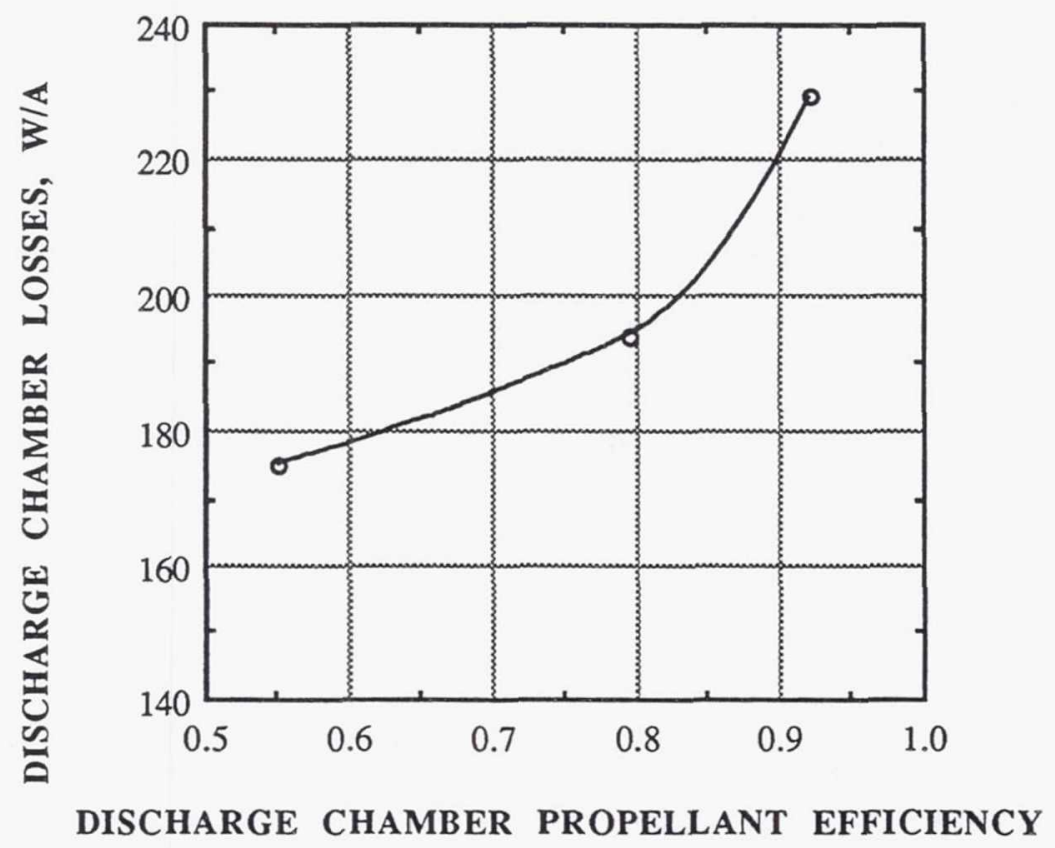

Fig. 7 Discharge chamber performance; 1.45 A beam current, $1.7 \mathrm{~kW}$. 


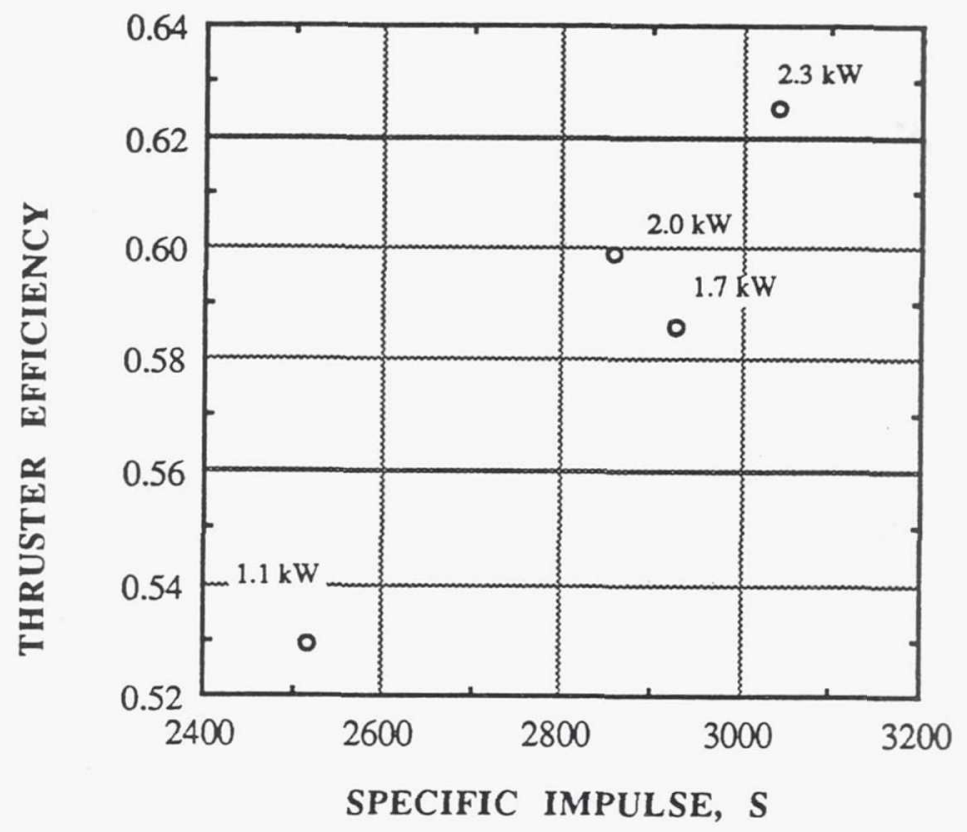

Fig. 8 Overall thruster performance.

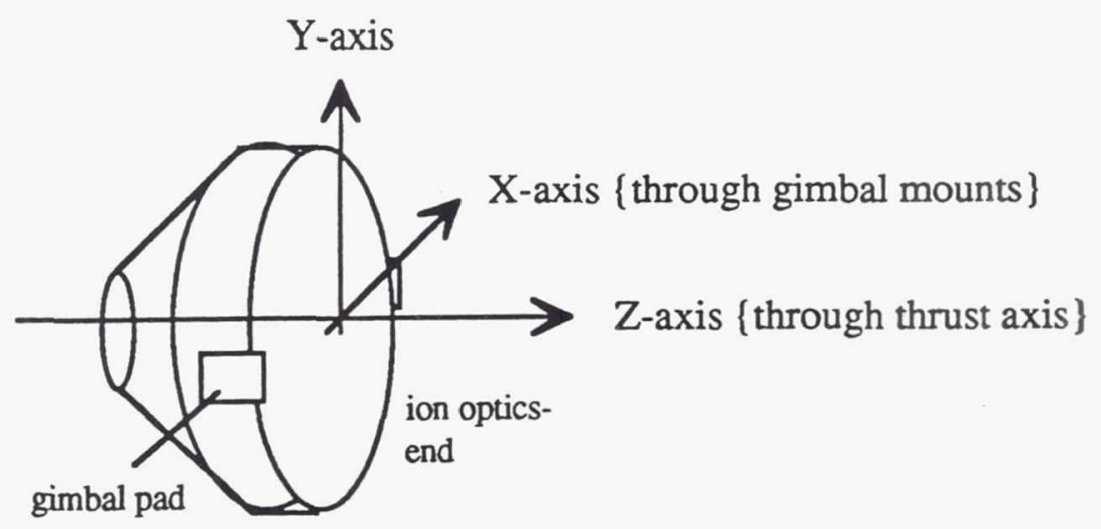

Fig. 9 Thruster reference axes for vibration tests. 


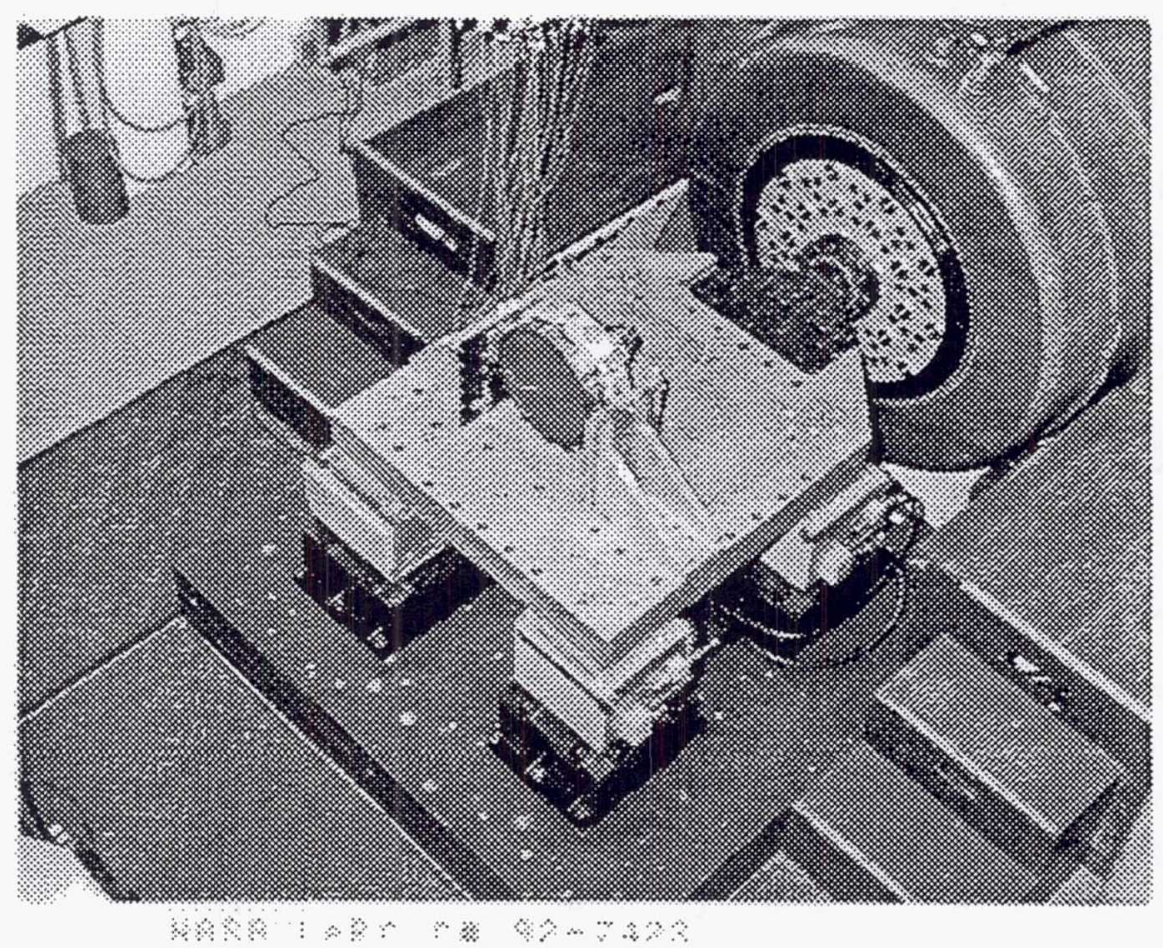

Fig. 10 Functional model thruster on vibration table.

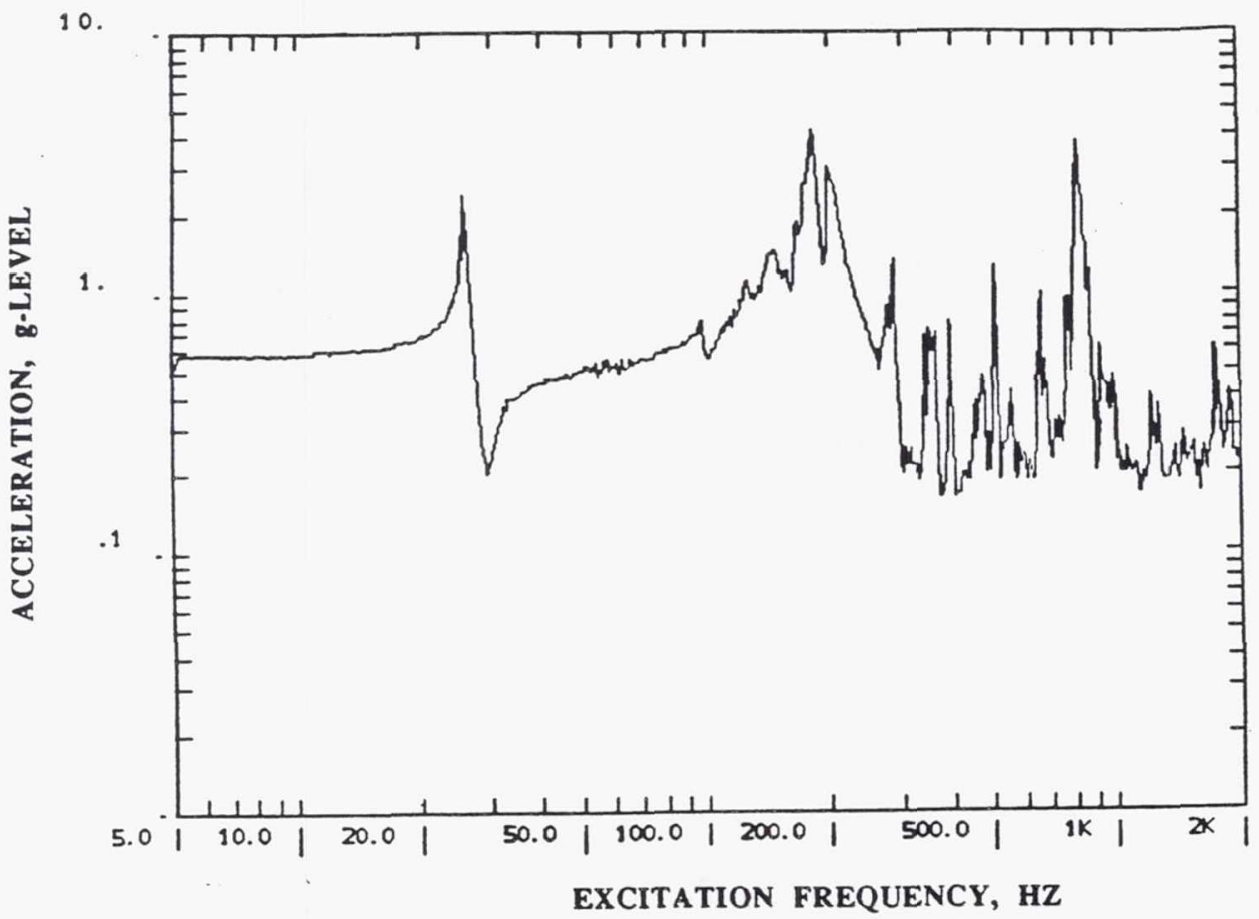

Fig. 11 Acceleration versus frequency plot for the discharge cathode; $0.5 \mathrm{~g}$ amplitude through Y-axis. 
Public reporting burden for this collection of information is estimated to average 1 hour per response, including the time for reviewing instructions, searching existing data sources, gathering and maintaining the data needed, and completing and reviewing the collection of information. Send comments regarding this burden estimate or any other aspect of this collection of information, including suggestions for reducing this burden, to Washington Headquarters Services, Directorate for Information Operations and Reports, 1215 Jefter
Davis Highway, Suite 1204. Arlington, VA 22202-4302, and to the Office of Management and Budget, Paperwork Reduction Project (0704-0188), Washington, DC 20503.

\begin{tabular}{|l|l|r|}
\hline 1. AGENCY USE ONLY (Leave blank) & $\begin{array}{r}\text { 2. REPORT DATE } \\
\text { June } 1993\end{array}$ & $\begin{array}{r}\text { 3. REPORT TYPE AND DATES COVERED } \\
\text { Technical Memorandum }\end{array}$ \\
\hline
\end{tabular}

4. TITLE AND SUBTITLE

Derated Ion Thruster Development Status

6. AUTHOR(S)

Michael J. Patterson, Thomas W. Haag, and George J. Williams, Jr.

7. PERFORMING ORGANIZATION NAME(S) AND ADDRESS(ES)

National Aeronautics and Space Administration

Lewis Research Center

Cleveland, Ohio 44135-3191

9. SPONSORING/MONITORING AGENCY NAME(S) AND ADDRESS(ES)

National Aeronautics and Space Administration

Washington, D.C. 20546-0001
5. FUNDING NUMBERS

WU-506-42-31

8. PERFORMING ORGANIZATION REPORT NUMBER

E-8029

10. SPONSORING/MONITORING AGENCY REPORT NUMBER

NASA TM-106292

AIAA-93-2225

\section{SUPPLEMENTARY NOTES}

Prepared for the 29th Joint Propulsion Conference and Exhibit cosponsored by the AIAA, SAE, ASME, and ASEE, Monterey, California, June 2830, 1993. Michael J. Patterson and Thomas W. Haag, NASA Lewis Research Center, and George J. Williams, Jr., Princeton University, Department of Mechanical and Aerospace Engineering, Princeton, New Jersey 08540. Responsible person, Michael J. Patterson, (216) 433-7481.

12a. DISTRIBUTIONAVAILABILITY STATEMENT

12b. DISTRIBUTION CODE

Unclassified -Unlimited

Subject Category 20

13. ABSTRACT (Maximum 200 words)

A $30 \mathrm{~cm}$ diameter xenon ion thruster is under development at NASA to provide an ion propulsion option for auxiliary and primary propulsion on missions of national interest. Specific efforts include thruster design optimizations, component life testing and validation, vibration testing, and performance characterizations. Under this program, the ion thruster will be brought to engineering model development status. This paper discusses the activities and preliminary test results to develop a $30 \mathrm{~cm}$ engineering model thruster.

\begin{tabular}{|c|c|c|}
\hline Ion thruster; Electric pro & lsion & \\
\hline $\begin{array}{l}\text { 17. SECURITY CLASSIFICATION } \\
\text { OF REPORT } \\
\text { Unclassified }\end{array}$ & $\begin{array}{l}\text { 18. SECURITY CLASSIFICATION } \\
\text { OF THIS PAGE } \\
\text { Unclassified }\end{array}$ & $\begin{array}{l}\text { 19. SECURITY CLASSIFICATION } \\
\text { OF ABSTRACT } \\
\text { Unclassified }\end{array}$ \\
\hline
\end{tabular}

